\title{
A PAIXÃO POLÍTICA DO MEDO NA CONCEPÇÃO DE HOBBES ${ }^{1}$
}

\author{
Cláudio R. C. Leivas \\ Universidade Federal de Pelotas
}

\begin{abstract}
The fear-passion-natural transmutes itself into fear-passion-politics when the human craftsman, at the founding pact of the State, artificially constructs legal regulatory mechanisms (punitive laws, for example) to maximize the effectiveness and positivity of fear as motivational disciplinatory factor. The presence of fear has peculiar plasticity with regard to the ties of natural philosophy with the Hobbesian moral and political. The natural fear of dying prematurely (contranatural death) in a pre-political state of nature is the fundamental reason for making moral and political agreements that boost the renunciation of natural rights. The political fear is fear of the public sword, that is, the fear of future bad consequences reserved for the individual or citizen that does not fulfill his political contractual obligations.
\end{abstract}

Keywords: will, passion, fear, contract.

Resumo: 0 medo-paixão-natural transmuda-se em medo-paixão-política quando 0 artesão humano, por ocasião do pacto fundador do Estado, constrói artificialmente mecanismos jurídicos reguladores (leis punitivas, por exemplo) para maximizar a eficácia e a positividade do medo como fator motivacional disciplinador. A presença do medo possui peculiar plasticidade no que concerne aos vínculos da filosofia natural com a moral e a política hobbesianas. 0 medo natural de morrer de forma prematura (morte contranatural) em um estado pré político de natureza é o motivo fundamental da confecção de acordos políticos e morais que impulsionam a renúncia aos direitos naturais. 0 medo político é o medo da espada pública, isto é, o medo das más consequências futuras reservadas ao indivíduo ou cidadão descumpridor de suas obrigações políticas contratuais.

Palavras-chave: vontade, paixão, medo, contrato.

\footnotetext{
${ }^{1}$ A paixão do medo é indissociável da vida e da obra de Hobbes. Conforme ele conta em sua biografia, seu nascimento se deu prematuramente devido ao excessivo medo de sua mãe em decorrência da notícia que a marinha de guerra espanhola se aproximava da Inglaterra. Além disso, continua Hobbes, tal preocupação de sua mãe com uma possivvel invasão espanhola fez com que ela parisse dois filhos num mesmo trabalho de parto: Hobbes diz que ele nasceu junto com o seu irmão-gêmeo: o medo.
} 


\section{0 medo como paixão}

O medo, antes de tudo, é uma paixão natural como o desejo e a esperança. $\mathrm{O}$ que significa dizer que é inerente à condição natural do homem a capacidade de temer, de desejar e de ter esperança. Paixões são tipos de movimentos vinculados ao movimento básico da vida. ${ }^{2}$ Viver sem paixões é algo impossível porque é a negação da própria vida e de seu movimento. A paixão chamada desejo é movimento de aproximação em relação aos objetos que agradam (e promovem o movimento vital) e a paixão chamada aversão é movimento de afastamento em relação aos objetos que desagradam (porque podem diminuir a intensidade do movimento vital ou decretar sua parada súbita).

A paixão do medo é a combinação da aversão com a opinião do possível dano causado pelo objeto temido. Por esse motivo, a paixão do medo envolve a representação do tempo, isto é, envolve prognósticos sobre males futuros amparados em lembranças de experiências passadas. Essas projeções sobre o futuro atendem pelo nome de prudência. ${ }^{3}$ De fato, em Do Cidadão o medo é concebido como a antevisão de um mal futuro (De Cive, p. 32). O medo é um desprazer esperado resguardado por um tempo que ainda não começou e compõe, com outras paixões (em especial, com a paixão esperança, ou seja, a antevisão de um bem futuro) o espaço da previsibilidade concernente às ações humanas.

Concebida a morte como o maior de todos os males (summum malum), o medo de morrer vem a ser o maior medo. A seguinte indagação parece aqui procedente: a morte é o mal supremo por que concebida como o encerramento natural da vida (tal é o caso da morte natural) ou é ela um mal supremo por que atrelada à abreviação não-natural da vida (tal é o caso

\footnotetext{
${ }^{2}$ A semelhança das paixões entre os homens é tão evidente que qualquer um, por introspecção, isto é, pelo exame interior de seus temores, desejos e esperanças, pode vir a conhecer os temores, desejos e esperanças dos outros homens com certo grau de certeza. Hobbes adverte o leitor que está falando da semelhança das paixões e não da semelhança dos objetos das paixões² (ou seja, das coisas que são temidas, desejadas e esperadas), uma vez que esses objetos são difíceis de conhecer "devido à dissimulação, à mentira, ao fingimento e às doutrinas errôneas" (Lev. Intro, p. 13).

${ }^{3}$ A esperança, por outro lado, é definida como uma combinação do desejo com a opinião que se alcançará o objeto desejado.
} 
da morte violenta)? A primeira parte da indagação pode ser explicada exclusivamente pela filosofia natural: a morte é o mal supremo por que é a cessação absoluta e definitiva do movimento da vida. A resolução da segunda parte da indagação requer a filosofia natural e a filosofia política: a morte é o mal supremo por que o tempo dado por natureza para perseverar o movimento que mantém vivo um indivíduo humano é passível de ser interrompido violentamente por outros indivíduos de sua espécie.

Esse último tipo de morte é um mal supremo contranatural por que interrompe o tempo reservado pela natureza para homens e mulheres viverem. A morte violenta, concebida como abreviação intempestiva do tempo natural da vida, produz um medo trágico por que excede o medo de morrer de morte natural. A possibilidade de morrer a qualquer instante gera um alto grau de ansiedade diante da incerteza e do desconhecimento relativos às reais intenções dos prováveis algozes. Em tal perspectiva, a racionalização do conflito conduz a um ataque desproporcional motivado pelo medo de morrer de morte violenta: o cálculo das consequências acoplado à incerteza e ao desconhecimento diante da morte num futuro próximo gera o medo de ser vitimado de forma prematura e a matemática da guerra passa a considerar todo homem um inimigo potencial. A guerra de todos contra todos congrega o medo de todos em relação a todos.

Compreendemos, mutatis mutandis, por que o desejo de preservação da vida pode ser considerado a outra face do medo da morte (em geral): desejar que o movimento vital não seja interrompido (no tempo ou antes do tempo) é o mesmo que temer que ele seja interrompido (no tempo ou antes do tempo). $\mathrm{O}$ agente causador da morte natural é a natureza. $\mathrm{O}$ agente causador da morte violenta é o próprio homem. Contra o medo da morte natural pouco ou nada se pode fazer: a mortalidade humana é de todos os axiomas o mais implacável por que assentado em um dado empírico inquestionável e absoluto. ${ }^{4}$ Mas o medo da morte violenta pode ser apaziguado com a instauração de um conjunto de regras cujo objetivo é

\footnotetext{
${ }^{4} \mathrm{~A}$ experiência nos mostra, contudo, que quando nos tornamos adultos, a certeza da morte faz com que nos conformemos com ela e, quando paramos de pensar intermitentemente nela, é o sinal de que 0 nosso medo de morrer perdeu sua força causadora de sofrimentos relacionados ao fim da nossa existência. A descoberta da finitude humana por uma criança é uma das experiências mais dramáticas de sua vida e provoca muito medo.
} 
substituir a situação de insegurança pela de segurança e a condição de guerra pela condição de paz.

Antes da instauração da paz civil a vida humana é absorvida numa luta incessante por sobrevivência. O mundo pré-político é moldado por poderes iguais conflitantes. De fato, a igualdade natural conduz ao conflito humano porque impede a instauração do domínio do poder de um só, de poucos ou de muitos, sobre os demais. Os que são iguais possuem poderes iguais e competem igualmente numa busca desesperada em armazenar poder e mais poder de forma rápida, eficaz e contínua de forma análoga aos homens e mulheres que armazenam alimentos e armamentos em tempo de guerra iminente. As causas da guerra humana são determinadas pela matemática do desejo de poder (poder + poder $=+$ poder), como podemos perceber a seguir:

a. Primeira causa da guerra humana: A competição.

A competição por poder e mais poder $(p+p)$ conduz a um conflito local e pontual na medida em que um indivíduo compete com outro detentor de poderes semelhantes ou iguais aos seus e que manifesta igual vontade de competir com ele por objetos selecionados pelo desejo de poder de cada um em particular. Competem por bens, honrarias, amigos, conhecimentos, etc. por que cada um desses itens representa uma soma ou adição de poder. A competição instaura um nível de insegurança que chamaremos de "alerta de grau médio".

b. Segunda causa da guerra humana: A desconfiança.

Um "alerta de grau máximo" é estabelecido com a inserção da segunda causa da guerra. Com efeito, quando não sei mais em quem confiar; quando amigos e parentes, por sua proximidade e afetividade representam uma ameaça igual ou maior que pessoas que eu desconheço; quando saio à rua e o objeto de meu medo muda a cada instante de forma e cor por que me é indecifrável ou invisível o agente causador de meu mal futuro é justificadamente razoável que eu passe a desconfiar de qualquer um que se aproxime e a competir com qualquer um que se aproxime. A desproporcionalidade do ataque (considerando-se o desconhecimento do poder do inimigo) é suscetível de levar a um estoque imprevisível de poder suplementar 
bem como a uma diminuição intolerável de poder ou mesmo a um poder de soma zero.

c. Terceira causa: Desejo de glória ou reputação

À competição e à desconfiança é adicionada a terceira e última causa do conflito humano: o desejo de glória ou reputação, que revela nossa predisposição em lutar se o poder que atribuímos internamente a nós mesmos não é reconhecido objetivamente por nossos pares. A subtração externa da avaliação do poder de um homem por outro homem é também um importante fator gerador de conflito. O resultado final da matemática do conflito desvela o desfecho final do estado de natureza: uma guerra que é de todos os homens contra todos os homens.

Improvável, portanto a existência de homens insensíveis à percepção do medo numa tal situação em que o risco de morte é constante e a vida humana é declaradamente “(a) empobrecida, (b) sórdida, (c) brutal e (d) curta" (leia-se: (a) desguarnecida de confortos básicos; (b) corrompida e degradante, logo moralmente repugnante; (c) há um alto risco de morte violenta; (d) o tempo natural de uma vida humana jamais consegue completar seu ciclo.

O que é decisivo em Hobbes é que ao medo negativo da morte violenta no estado natural ele acrescenta um medo positivo atrelado às más consequências resultantes de se faltar com a palavra dada numa condição contratual. ${ }^{5} \mathrm{O}$ medo de ser punido pela espada pública é o componente motivacional imprescindível para a real efetivação de condições contratuais estabelecidas pela racionalidade pró-paz descoberta com o surgimento das leis naturais. ${ }^{6}$ A validade dos pactos é de forma alguma satisfeita pela mera

${ }^{5}$ Dizer que esse tipo de medo é constitutivo das sociedades humanas é dizer que o Estado, não obstante criado pela razão humana o é também pela paixão humana.

${ }^{6}$ Leis naturais são leis estabelecidas pela razão calculadora prudencial que se expressam na forma de ditados que dizem o que fazer para superar a seguinte contradição fundamental da condição primeira do homem: o desejo básico de preservação da vida, quando posicionado no plano das interações humanas numa situação em que todos lutam para que a série de desejos permaneça aberta (pois fechar a série é morrer), acaba por conduzir a uma guerra de vontades que culmina numa situação de insegurança determinada pelo constante risco de morte. A superação dessa contradição requer o abandono do estado natural. 0 mecanismo artificial criado pelo homem para servir de suporte a esse abandono é 0 pacto ou contrato social. 
razoabilidade de suas cláusulas já que um cálculo bem feito é pouco convincente para amarrar um homem e frear a ambição humana. As palavras são vazias e inócuas sem o conteúdo motivacional do medo.

O medo de que se trata aqui é o medo como paixão política: esse tipo de medo é positivo por que imprescindível ao advento de sociedades humanas: ele forma uma espécie de cumplicidade com a razão calculadora contratual com vista a opor-se àquelas paixões naturais (como a cobiça e a glória) determinantes do interesse próprio imediatista e carregadas de sementes da guerra. A paixão política do medo é o componente passional que pode compatibilizar as razões da paz com a paixão pela paz. Ao fazer parte de um cálculo pró-paz a paixão-medo marca presença na origem das obrigações contratuais e da obediência civil.

Contudo, o ato de sentir medo não se encontra confinado ao próprio medo. Sentir medo pode ser compatível com uma série de artifícios criados pelo homem para deixar de sentir medo ou pelo menos sentir menos o medo (por exemplo, um medo tolerável que não cause grande sofrimento e ansiedade nas pessoas, como ocorre hoje em dia nos países que resolveram seu problema de insegurança interna e externa). A criação do maior de todos os artifícios humanos, o poder político do Estado-Leviatã, tem o medo como causa e como efeito. $\mathrm{O}$ medo de ser punido publicamente pelo descumprimento de cláusulas contratuais relativas ao ato proto fundador do Estado é condição necessária dos pactos válidos. Uma vez criado o Leviatã, o medo das punições públicas é incorporado ao imaginário coletivo dos cidadãos para dar solidez às leis civis (Hobbes afirma que a obediência civil é a base da conservação dos estados públicos).

\section{A função do medo nas relações contratuais}

Os vínculos das palavras (numa situação contratual) são insuficientes sem a força motivacional do medo. As palavras dos homens quebram facilmente como taças de cristal. ${ }^{7}$ Com efeito, se o ato de se fazer pactos $\left(2^{\mathrm{a}}\right.$

\footnotetext{
70 medo de que a outra parte no pacto não cumpra suas promessas é o medo de alguém igual a mim, uma vez que na condição primeira do homem todos são iguais por natureza. Nessa condição, alguém que possui poderes iguais aos meus é um convite para o não cumprimento de minha parte no pacto, porque há oportunidades reais de eu vir a conseguir benefícios extras sobre ele ao violar o pacto. Esses benefícios, no estado natural, significam uma supervalorização da moeda mais cobiçada e desejada nesse estado: a posse de "poder e mais poder" (power after power).
} 
lei natural) no estado natural é determinantemente precário para se buscar a paz ( $1^{\text {a }}$ lei natural fundamental) é preciso o surgimento de um poder diferenciado para originar um medo diferenciado que seja suficiente para forçar os homens a cumprirem os pactos feitos ( $3^{\mathrm{a}}$ lei natural).

O poder político do Estado é um poder diferenciado (isto é, diferente dos poderes naturais humanos) por que concebido como um poder composto: o poder político do estado moderno é um somatório de todos os poderes e forças que cada homem consentiu em transferir ao futuro governante como condição de preservação da vida e constituição da paz pública. $\mathrm{O}$ medo diferenciado é o medo das más consequências resultantes das punições aplicadas pelo poder político àqueles que transgridem os contratos e desobedecem as leis civis. O medo como paixão política situa-se na base contratual de formação do estado moderno e é indispensável à sua conservação.

O medo potencializado do poder político não é para causar sofrimento e ansiedade na mente do cidadão obediente. ${ }^{8}$ Os inimigos do Leviatã é que devem sentir toda a extensão do medo da espada pública: os que planejam sua destruição incitando a população com opiniões contrárias à ordem pública e os que sustentam a desobediência civil. Esses continuariam a sentir os desconfortos do medo na condição de paz civil: medo de serem aprisionados, de terem suas propriedades confiscadas e o medo de morrer de morte violenta via decreto público.

Uma das razões da violência institucionalizada dirigida a essa espécie de transgressor da ordem e da lei é que tal inimigo do Estado é um indivíduo com vontade privada que não participou do pacto que instituiu o Estado e dessa forma continua em estado natural (livre, sem amarras e na posse de seus direitos naturais em toda sua extensão) na esfera da ordem pública. O que é particularmente interessante é que também o mandatário supremo (isto é, o soberano) não participa do pacto de fundação do Estado. Os cidadãos disciplinados, cumpridores de suas promessas contratuais, por que nada devem nada tem a temer. O dever do Estado é afirmado pelo objetivo último de sua instituição: salus populis (a segurança do povo). ${ }^{9}$

\footnotetext{
${ }^{8} \mathrm{O}$ adágio popular "quem não deve não teme" pode aqui ser usado a título explicativo.

${ }^{9} \mathrm{O}$ que significa que o dever substancial de um Estado é dar garantias para que os cidadãos vivam em segurança. (Um exame da segurança sentida pelos cidadãos nos estados nacionais atuais levaria para além do objetivo deste estudo. Não obstante isso, é perceptível a sensação de segurança em países
} 


\section{0 medo e a representação do tempo}

O medo é uma paixão que leva a razão prudencial a efetuar representações no tempo de forma a avaliar possíveis danos (males) que coloquem em risco a preservação da vida num futuro próximo. Enquanto a paixão-esperança remete à expectativa de um bem futuro, a paixão-medo remete à expectativa de um mal futuro (Elem., p. 110). Acionada pelo medo, a representação no tempo presente de um mal futuro engendra mecanismos de defesa com o propósito de contornar ou neutralizar o objeto do medo:

Pois em todo homem existe certo grau, sempre elevado, de medo, através do qual ele concebe o mal que venha a sofrer como sendo o maior de todos. E assim, por uma necessidade natural, ele o esquiva o mais possível... Ora, quando alguém chega a esse grau de medo, tudo o que dele podemos esperar é que se salve, pela luta ou pela fuga. (De Cive, p. 56).

A gradação do medo é natural ao homem e funciona como critério individual de avaliação de males futuros. O objeto do medo é sempre superestimado em seu potencial de destruição da vida. A percepção de um medo em escala máxima arregimenta imediatamente mecanismos antecipatórios para fazer frente a um objeto identificado como um mal em escala máxima. O movimento de fuga é uma das hipóteses levantadas por Hobbes para quem sente medo deixar de sentir o medo. Mas ele não pensa que "fugir seja o único efeito do medo", pois "quem sente medo também ocorre desconfiar, suspeitar, acautelar-se e até mesmo agir de modo a não mais temer" (De Cive, p. 32). No Elementos da lei a alternativa para se livrar do medo de morrer é posta nos seguintes termos: "Matar é o objetivo daqueles que odeiam, para se livrarem a si mesmos do medo" (p. 109). De fato, uma das maneiras de matar o medo da morte é aniquilar o objeto causador desse medo.

Considerado o medo o indicador passional oficial na classificação de males futuros, o grau de insegurança detectado por um indivíduo em condição natural é avaliado pela representação do grau alcançado por seu

que conseguiram resolver seus problemas estruturais e econômicos e a sensação de insegurança naqueles que não conseguiram esse propósito.) 
medo. No estado natural a gradação do medo pode vir a atingir uma elevação hiperbólica coletiva se as vontades de todos os habitantes do estado natural manifestam uma tendência em bloco para entrar em guerra cada um contra cada um. ${ }^{10}$ A guerra de todos contra todos seria então estruturada pelo conjunto volitivo de todos os medos.

A necessária diminuição do alto grau de insegurança no estado natural (explico: necessária por que sem o abrandamento do medo não há espaço para os pactos válidos) é articulada pelo próprio medo em associação com a razão prudencial calculadora. Pois de acordo com o que diz Hobbes, no ato preparatório do abandono do estado natural "a paixão com que se pode contar é o medo". O medo diferenciado da espada pública, isto é, o medo das punições executadas pelo poder diferenciado da autoridade política soberana é desse ponto em diante "o maior medo", surgindo "em grau suficiente para levar os homens a cumprirem as suas promessas" (Lev., p. 122).

\section{A paixão política do medo}

Um tipo de medo deve ser removido para que outro tipo de medo se instaure: deve ser removido o medo que leva os homens a se atacarem mutuamente (numa busca incessante por domínio sobre os demais); deve ser instaurado o medo que impele os homens a respeitarem as regras da paz e da civilização. Hobbes acreditava verdadeiramente que a ameaça e o "medo do castigo" imputado pelo Estado poderiam conduzir efetivamente os homens "ao cumprimento de seus pactos e à observância das leis naturais" (Lev., p. 143). Ele percebeu que o caráter plástico do medo seria útil na formatação da razão pública do Estado e que a invenção de um poder diferente dos poderes individuais poderia substituir (mesmo que parcialmente) os efeitos negativos do medo natural pelos efeitos positivos do medo político. A paixão política do medo é identificada a seguir como $o$ medo de um poder coercitivo:

\footnotetext{
10 Isso ocorre quando a vontade ou o querer de cada um vem a ser uma vontade ou um querer direcionado para causar o mal a cada outro num futuro bem próximo.
} 
Porque os vínculos das palavras são demasiado fracos para refrear a ambição, a avareza, a cólera e outras paixões dos homens, se não houver o medo de algum poder coercitivo coisa impossível de supor na condição de simples natureza, em que os homens são todos iguais, e juízes do acerto dos seus próprios medos (Lev., p. 119).

A paixão política do medo é uma paixão disciplinadora: "De todas as paixões, a que menos faz os homens tender a violar as leis é o medo. Mais: excetuando algumas naturezas generosas, é a única coisa que leva os homens a respeitá-las" (Lev., p. 253). O medo é definitivamente um importante fator gerador de obediência civil. ${ }^{11}$ A vontade política soberana, geradora do grande medo político, é poderosa o suficiente para jamais sentir o medo. Com efeito, o estado político moderno é "feito de maneira que nunca tenha medo" (Lev., p. 271). O Deus da política e o Deus da religião podem até mesmo disputar terreno quando se trata de atemorizar os homens para conseguir a obediência deles aos seus códigos de leis:

A paixão com que se pode contar é o medo, o qual pode ter dois objetos extremamente gerais: um é o poder dos espíritos invisíveis, e o outro é o poder dos homens que se pode ofender. Destes dois, embora o primeiro seja o maior poder, mesmo assim o medo do segundo é geralmente o maior medo. O medo dos primeiros é, em cada homem, a sua própria religião, a qual surge na natureza do homem antes da sociedade civil. Já o segundo [medo] não surge antes disso, ou pelo menos não em grau suficiente para levar os homens a cumprirem as suas promessas (Lev., p. 122).

A vontade política e a vontade divina são fontes de obrigações que se expressam, reciprocamente, como leis civis e leis divinas. O medo é a própria vontade de preservar o movimento apaixonado da vida, pois uma vez que "a vontade de fazer é desejo e a vontade de omitir é medo, as causas do desejo e do medo são também as causas da nossa vontade"

\footnotetext{
${ }^{11}$ A representação imaginária do medo das punições em decorrência da desobediência às leis civis é mais eficaz e econômica do que os suplícios e ou execuções em praça pública, parte constitutiva da vida nas cidades medievais.
} 
(Elem., p. 145). A paixão do medo é a chave da passagem do estado de guerra ao estado de paz, pois é preciso que o querer natural (= vontade natural) do homem esteja suficientemente motivado para aceitar a razoabilidade da fundação do querer político (= vontade política). Havendo suficiente motivação e suficiente razão para a efetivação do pacto fundador da sociedade, o grau de segurança necessário para que as leis naturais se tornem operantes é alcançado e o processo da representação política é posto em funcionamento no ato artificial de criação da realidade política. A realidade política foi inventada pela necessidade que os homens tinham de superar os limites impostos a eles pela realidade natural.

A modernidade da política, inaugurada de forma sistemática por Hobbes, tem como suporte uma paixão que em outros tempos era associada a uma virtude negativa por que considerada o oposto da coragem: Hobbes transformou o medo como covardia numa paixão avassaladora e indispensável para a fundação do estado político moderno. 


\section{Referências:}

BERNHARDT, J. Hobbes. Paris: PUF, 1989.

GOLDSMITH, M.M. Hobbes's Science of Politics. New York: Columbia University Press, 1966.

GRUNDSTEIN, N. The Future of Prudence: Pure Strategy and Aristotelian and Hobbesian Strategists. Ohio: A Zeus Book, 1983.

HOBBES, T. De Cive ou les fondements de la politique (tradução de S. Sorbière), Paris: Éditions Sirey, 1981.

. De Homine, tradução para o francês de Paul-Marie Maurin, Paris:

Librairie Scientifique et Technique, 1974.

. De Homine e De Cive, editado por B. Gert com o título Man and Citizen, Cambridge: Haackett Publishing Company, 1991.

. De la Nature Humaine, traduzido do inglês para o francês pelo barão d'Hilbach, comentário de E. Roux, Saint-Amand-Montrond: Actes Sud, 1997.

Do Cidadão, tradução de Renato Janine Ribeiro. São Paulo: Martins Fontes, 1993.

Leviatã, edição Martins Fontes, São Paulo, 2003 (traduzido para o português por João Paulo Monteiro e Maria Beatriz Nizza da Silva).

. Leviathan, editado com uma introdução de C. B. Macpherson, London, Penguin Books, 1985.

Natureza Humana (primeira parte dos Elementos da Lei), editado pela Imprensa Nacional - Casa da Moeda, Lisboa 1983.

. The English Works of Thomas Hobbes, editado por W. Molesworth. London: 1839 (edição eletrônica em CD-ROM - Intelex Corporation, 1993).

LEIJENHORST, C. The Mechanisation of Aristotelianism: the late Aristotelian setting of Thomas Hobbes' Natural Philosophy. Boston: Brill, 2002.

LEIVAS, C.R.C. "Situação de Conflito e Condição de Obrigação em Hobbes", in: Disputatio: Revista Internacional de Filosofia Analítica, Gradiva Publicações, 2000. MALHERBE, M. Hobbes: Hobbes ou L'oeuvre de la Raison. Paris: Vrin, 2000. MARTINICH, A. P. A Hobbes Dictionary. Cambridge: Blackwell Publishers, 1996. MINTZ, S. The Hunting of Leviathan. Cambridge: CUP, 1970.

MOREAU, P-F. Hobbes: Philosophie, science religion. Paris: P.U.F, 1989.

PETERS, R. Hobbes. London: Peregrine Books, 1967.

ROGERS G. A. J. and RYAN, A. (eds.), Perspectives on Thomas Hobbes. Oxford: Clarendon Press, 1998. 
SORELL, T. Hobbes. London and New York: Routledge, 1991.

SPRAGENS, T. A. The Politics of Motion. London: The Trinity Press, 1973.

TUCK, R. Hobbes. Oxford: Oxford University Press, 1989.

ZARKA, Y.C. La Décision Métaphysique de Hobbes. Paris: Vrin, 1987.

Email: clleivas@hotmail.com

Recebido: Abril/2011

Aprovado: Maio/2011 